\title{
LANAP, Periodontics and Beyond: A Review
}

\author{
Amrita Jha ${ }^{1 *}$, Vivek Gupta ${ }^{2}$, Roopa Adinarayan ${ }^{3}$ \\ 'Department of Periodontology and Oral Implantology, Rama Dental College, Hospital and Research Centre Kanpur, U.P. \\ India \\ ${ }^{2}$ Department of Periodontology and Oral Implantology, Dental Institute RIMS Ranchi, Jharkhand, India \\ ${ }^{3}$ Department of Periodontology and Oral Implantology, Rama Dental College, Hospital and Research Centre Kanpur, U.P. \\ India
}

\author{
*Correspondence to \\ Amrita Jha, PG Student; Department \\ of Periodontology and Oral \\ Implantology, Rama Dental College, \\ Hospital and Research Centre \\ Kanpur, U.P. India. \\ Address: Dr. Amrita Jha, A-502, \\ Navrattan appt. plot no.7A sec 23 \\ Dwarka New Delhi-110075. \\ Tel: +91 9717203555: \\ Fax 05122583875 \\ Email: amrita.jha29@gmail.com
}

Published online 20 March 2018

\begin{abstract}
Laser has emerged as an adjunct in several treatment modalities in dentistry in the past few decades. This less invasive bladeless technique is bringing revolutionary outcomes in a plethora of periodontal treatment procedures as well. A unique ameliorative approach termed LANAP, described as laser-assisted new attachment procedure was developed by Gregg and McCarthy. In 1990 they introduced an innovative treatment for diseases of gums incorporating pulsed neodymium yttrium aluminum garnet (Nd: YAG) $1064 \mathrm{~nm}$ wavelength laser (PerioLase MVP7). The LANAP concept was endorsed by Yukna et al who conducted a study according to the protocol reinforced at the1996 world workshop in periodontics, which established specific histologic criteria to prove regeneration. Yukna's histological study found that regeneration of the periodontally compromised root could be achieved by Nd: YAG laser. LANAP facilitates refurbishing of new tissues from supporting structures of the periodontium wherein the unhealthy surface of the roots exhibit pristine attachments in human beings. This paper is a review providing a detailed report of LANAP from its inception to recent advances.

Keywords: LANAP; Laser; Nd:YAG; Periodontics; Periodontal regeneration.
\end{abstract}

\section{Introduction}

The paradigm of periodontal treatment is shifting from an arena of resective to more of regenerative and reconstructive procedures. The ultimate goal of all therapies pertaining to gums and periodontium is regenerating supporting structures around teeth. ${ }^{1}$ Development of some less invasive but effective procedures has become the need of the hour for patients and clinicians. Many times, conventional surgical procedures are not welcomed by the patients due to the subjective and objective apprehensions for pain, swelling, root exposure and postoperative discomfort. ${ }^{2}$ Nonsurgical therapy does not resolve the disease completely. Regeneration in a true sense refers to the formation of new bone, cementum, and periodontal ligament. It was observed that laser-assisted new attachment procedure (LANAP) could initiate regeneration of the affected periodontal tissues in human beings, and new connective tissue attachment mediated by cementum could be seen. ${ }^{2-4}$ These findings were based on a recent study which confirmed replacement of diseased tissues of root with new cementum, bone, and periodontal ligament, which reflects periodontal regeneration. Millennium dental technologies came up with an innovative therapy by PerioLase MVP-7, which is neodymium yttrium aluminum garnet (Nd: YAG) 1064 $\mathrm{nm}$ laser in free running pulsed mode as an adjunct as well as an alternative to traditional periodontal surgeries. Researchers show that LANAP performed with Nd:YAG laser (PerioLase MVP-7) facilitates not only periodontal regeneration but also minimal bleeding, edema, and postoperative uneasiness. ${ }^{4}$ Clinical efficacy of LANAP still has limited evidence and is in its infant stage. This review intends to elaborate the substantiation of clinical success of LANAP in terms of regeneration as well as the dissension of LANAP.

\section{Methods}

The dental literature was searched through Medline, PubMed Central (PMC), PubMed and Google for term "LANAP". Various journals and review papers were referred. Manual and computerized search on LANAP, Lasers, and Periodontics showed 278 articles.

\section{Lasers, Periodontal Treatment - A Brief History}

The first laser was invented by Theodore Maiman in 1960 at Hughes research lab in Malibu California. Myers and Myers in 1989 proposed the use of Nd:YAG laser in oral surgical procedures involving soft tissues. ${ }^{4-7}$

Historically, gingivectomy was the treatment of choice for pocket elimination described by Pierre Fauchard in 
the 18th century. ${ }^{8}$ Schluger in 1949 , described enhanced methods for accessing the alveolar bone. ${ }^{9}$ In 1954, Nabers ${ }^{10}$ proposed elevation of full thickness mucoperiosteal flap. In 1980, GTR with the help of barrier membrane was used to maintain space and interrupt apical down growth of the gingival epithelium. ${ }^{11}$

Recent advances include the use of biologic mediators and tissue engineering in regenerative procedures wherein they stimulate the release of growth factors like PGDF, IGF-1and BMPs. They possess remarkable potential for stimulation of bone and cementum regeneration but without predictive clinical outcomes. ${ }^{11-15}$

Nevertheless, even with such progress, predictable regeneration is still an enigma, and the quest for the "holy grail" to revive periodontal tissues persists. Dentists have used lasers in various treatment techniques. More than a decade ago, Gregg and McCarthy ${ }^{16,17}$ published a research recommending a possible regenerative therapy of ailing periodontal tissues using exclusively Nd:YAG $1064 \mathrm{~nm}$ laser in free running pulsed mode. The concept evolved in the 1990s, and its use was later advocated for achieving bone regeneration. ${ }^{16-18}$

\section{Laser Radiation}

Laser radiation is more or less in a single wavelength (monochromaticity), has directionality, coherence and brightness. ${ }^{19}$ There are different types of lasers with varying degrees of rays transpiercing the tissues based on the property of reflection, scattering or absorption. In oral tissue, absorption is due to the presence of free water molecules, pigments, proteins, and other macromolecules. ${ }^{20}$ Laser potential is affected by the absorption coefficient in water. Pigments and proteins also influence absorption. ${ }^{19,20} \mathrm{Nd}$ :YAG and diode are soft tissue lasers with greater depth of penetration whereas $\mathrm{CO} 2$, erbium-doped yttrium aluminium garnet laser (Er:YAG) have lesser penetration. ${ }^{21}$

\section{Effect of Laser on Tissues}

1. Photothermal ablation: overheated tip coagulates the tissue

2. Thermal side effects and hemostasis

3. Disinfection and detoxification effects: Nd:YAG laser selectively devitalizes some pigmented bacteria. Lasers cause ablation of bacterial endotoxins and inhibition of bacterial colonization.

4. Biomodulation of cells causes better healing of tissues. ${ }^{22,23}$

LANAP has a specific protocol which is described as follows: LANAP is said to have well research proven operating specifications. The innovators, Gregg and McCarthy formulated a set of criterion for LANAP which received Food and Drug Administration (FDA) clearance in 2004. ${ }^{24}$ This single laser surgical treatment with a 1064 $\mathrm{nm}$ free running pulsed Nd:YAG (6 W PerioLase MVP) laser is patented by Millennium Dental Technologies
Cerritos, CA, USA. ${ }^{26}$

Patients needing standard periodontal treatment with pocket depth $(\mathrm{PD}) \geq 4 \mathrm{~mm}$ are indicated for LANAP. ${ }^{4}$ The essence of the success of LANAP lies in the systematic way in which it is done. Generally, the procedure is performed in one or two non-adjacent quadrants. ${ }^{25-28}$

1. The patient is profoundly anesthetized initially with a local anesthetic to properly access the extent of intrabony flaw with a probe.

2. An optic fiber tip measuring $0.3-0.4 \mu$ is placed parallel to the root surface, to carry away the epithelium lining of the pocket in coronal to apical motion to reflect the gingival flap. The first pass laser or troughing dissipates energy at $4 \mathrm{~W}$, free running 100 milliseconds pulse expels the unhealthy lining of the pocket. The duration of the pulse is short.

3. Calcified plaque adherent to the root surface is removed. 4. Selective photothermolysis removes unhealthy, infected and inflamed epithelium of the pocket sparing the intact connective tissue separation of the layers of tissues at rete pegs and ridges level.

5. Laser used with utmost precision in variation of energy density, pulse duration and calculated rate of repetition leads to antiseptic hemostasis and tissue ablation.

6 . The second pass with a variation in parameters, energy dissipation at $4 \mathrm{~W} 650$ milliseconds pulse allows reentry of the pocket. This establishes a sticky fibrin blood clot which secures the pocket from detritus matter and perpetuates healing from inside out.

7. The pocket is closed by compressing gingival tissues against the root surface which creates a firm fibrin clot. No placement of sutures or surgical glue. Splinting of grade II mobile teeth.

8. Interferences minimized by proper occlusal adjustments to decrease traumatic forces simultaneously creating a balance with long axis forces are vital elements of the LANAP protocol.

At the end of the procedure patients are given postoperative instructions pertaining to LANAP protocol including proper diet specifications along with oral hygiene directives with a lot of emphasis on continued periodontal maintenance. Patients are recalled at an interval of 1 week, one month and thereafter every three months for periodontal maintenance. In order to allow sufficient recovery time for tissues to heal at cementumfiber PDL interface, probing is ruled out for next 6 months to 1 year.

LANAP shows: a remarkable prediction for regeneration which can be attributed to,

- Laser energy is selectively and intensely absorbed only by the diseased tissues discriminating healthy adjacent tissues.

- Bactericidal effect on pigmented bacteria.

- A thermal fibrin clot secures the pocket crevice.

- Coronal to apical movement of epithelium is restricted by clot acting as a barrier. 
- The epithelium is allowed to heal inside out by activation of pluripotent cells from periodontium.

LANAP, when compared to conventional periodontal surgery, provided some elusive advantages like,

- Minimally invasive with better patient compliance

- Decreased postoperative pain and morbidity

- Less likely to develop hypersensitivity

- Less prone to recession

- Faster healing

- Natural teeth as well as implant both show regeneration of the surrounding tissues. $3,28,29$

\section{Results}

Yukna et al, McAllister, Nevins et al, Brown and Harris et al studies are some of the major studies with definite positive results for LANAP. ${ }^{1-3,29,30}$ However, some shortcomings in the results are also reflected by few other studies mentioned in Discussion section.

\section{Discussion}

LANAP Endorsing Literature

Yukna et $\mathrm{al}^{1,31}$ conducted one of the most valid histological studies and were the first to publish and prove, positive results of LANAP therapy in comparison with traditional periodontal surgery. This longitudinal, blinded study was able to indubitably reveal successful results with LANAP. Histologic evidence of all sites treated by LANAP displayed regeneration as compared to no regeneration in control sites. Published by Yukna et al in 2007 this was a definite proof-of-principle study exhibiting the possibility of regeneration with LANAP. While treating intrabony defects, new cementum and new connective tissue attachment adjacent to alveolar bone were seen but no long-junctional epithelium was observed.

McAllister conducted a study in 2009 on 3 cases which were conclusive of positive results of LANAP using the Nd:YAG PerioLase MVP-7 laser for the treatment of moderate-to-severe adult periodontitis in routine dental practice. All three cases reflected clear radiographic bone regeneration following LANAP. He concluded that LANAP unveils a less invasive approach and shows better patient compliance. ${ }^{29}$

Nevins et al in 2012 studied the healing process histological aspect while incorporating LANAP protocol to treat intrabony defects. Eight patients with 930 sites were taken up for study with an average of 19.38 teeth per patient (assuming 6 sites per tooth). Incredible results following LANAP treatment were seen in severe periodontitis. ${ }^{2}$

Brown's recent research on PerioLase MVP-7 laser, a free running Nd:YAG laser, demonstrated that LANAP outcomes are phenomenal and comparable to conventional periodontal surgery while facilitating regeneration. ${ }^{3}$

A split mouth randomized multicenter trial guided by Harris et al in 2014 advocated that LANAP protocol could produce a systemic effect on subgingival wound healing and minimal postoperative discomfort to the patient. ${ }^{30}$

\section{Recent Advancement of LANAP}

LANAP and Implants

Implants have brought up a phenomenal revolution in the field of dentistry regarding the replacement of missing teeth.

With a global annual increase in the number of implants, complications related to implants are following simultaneously, of which, perimucositis and perimplantitis seem to be most common ones. Millennium technologies have come up with a modification of LANAP for implant known as LAPIP protocol for implants. ${ }^{32-36}$

\section{The LAPIP Protocol}

McCarthy brought forth the concept of LAPIP, "LaserAssisted Peri-Implantitis Procedure" as a modification of LANAP which could be used in diseased implants. Laser, removes inflamed pocket tissue, disrupt biofilms, and decontaminate the root/implant surface. Decrease in inflammation and a laser-induced hemostasis further decontaminates the tissue creating a durable blood clot to close the system.

LAPIP brings back diseased structure to healthy states, promotes bone and tissue regeneration, and the most commendable feature is that the procedure is performed on implant without damaging it. A single appointment might be sufficient. Since no flap is reflected, it even leaves chances for other therapies in the future. The LAPIP protocol recommends the PerioLase MVP-7, a Nd:YAG "free-running" pulsed laser, to treat periimplantitis. ${ }^{32-36}$ Suzuki, in a Nov 2015 compendium mentioned a few studies in relation to implants complications, where their management is still an enigma. ${ }^{36} \mathrm{He}$ mentioned a laboratory study by Harris and Yessik which could find an effect of pulsed Nd:YAG laser in removing pigmented bacteria exclusively while sparing the adjacent areas. ${ }^{37}$

Another study in 1992 by Cobb et al, where, 3 bacterial groups (Aggregatibacter actinomycetecomitans, Porphyromonas gingivalis, and Prevotella intermedia) were found to be low in periodontal pockets after laser treatment in comparison to non-treated site. ${ }^{38}$ Twentytwo years later, McCawley observed Nd:YAG laser effectivity on putative bacterial agents in the pockets of 20 human patients. Pathogens were estimated to be below culture detection limits. ${ }^{39}$

Giannelli et al conducted a study on the effects of Nd:YAG laser an In vitro study. He concluded that the use of Nd:YAG laser appears as a solution to treat periimplantitis. $^{40}$

Some research reported that both soft tissue lasers (Nd:YAG, diode, CO2), as well as hard tissue lasers, can have an untoward effect on implant surfaces, such as undesirable temperature rise. Temperature increase of more than $10^{\circ} \mathrm{C}$ can compromise bone vitality. Little is 
known about the effect of laser irradiation on temperature rise on the implant surface. ${ }^{42-45}$ Therefore, laser-assisted peri-implant procedure should be practiced only after a rigorous authorized training program.

\section{LANAP and Diabetes}

Long described the advantage of the LANAP protocol performed with the PerioLase MVP-7, free running pulsed Nd:YAG laser in treating diabetic patients with Type IV periodontitis. This therapy has been shown to provide new bone growth and stability in patients with type IV chronic periodontitis, reestablish new cementum-mediated periodontal ligament attachment, and induce periodontal regeneration. $\mathrm{He}$ also demonstrated the correlation between uncontrolled DM and its effect on chronic adult periodontitis. The patient's HbAlc levels and periodontal health exhibited marked improvement after LANAP treatment. ${ }^{27}$ Long 's study is also supported by studies from Aemaimanan et $\mathrm{al}^{50}$ who reported a significant prevalence of red complex bacteria in subgingival biofilm of patients with poor glycemic control. These pathogens associated with periodontitis were significantly higher in diabetic patients compared to control groups with good glycemic control. De Andrade et al noted that Nd:YAG laser combined with conventional treatment significantly reduced bacteria in class II furcations. ${ }^{51}$

A study by McCraken could show that the combination of LANAP protocol and orthodontics is a truly innovative concept and has quite positive outcomes. ${ }^{52}$

LANAP as True Regeneration

Food and Drug Administration 510(k) approved PerioLase MVP-7 in 2016 as the only appliance in medicine and dentistry with which regeneration of the cementum mediated attachment apparatus could be achieved when LANAP protocol was followed. The clearance from FDA states that it is possible to regrow alveolar bone, not just repair the damage done by gingival disease, but achieve a true regeneration of all three components needed for full function. It achieves the gold standard of regeneration. ${ }^{53}$

\section{Some Dissensions for LANAP}

Western society of periodontics advocated that proper scientific proofs should be thoroughly checked and pondered upon by clinicians before getting handy into the practice for LANAP. The evidence is there but few in numbers, only 8 works are categorized as research articles. There are no proper studies to figure out the substantiation of LANAP in detecting diseased and healthy tissues. ${ }^{54}$ Behdin et al in 2015 conducted a systematic review and meta-analysis on effect of laser in periodontal therapy. Their study could not conclude LANAP to have better results as compared to traditional ways but they also suggested more randomized clinical trials for better assessment. ${ }^{55}$

Shah et al in 2015 concluded that an adequate sample size, randomized trial with controls and specific treatment goals and criteria are the essential components of a good study. An appropriate time-line is a prerequisite for effective and long-term results. They highlighted that Nd:YAG lasers did not have better results over conventional periodontal therapy in the treatment of initial periodontitis. ${ }^{56}$

\section{Conclusion}

In dentistry, lasers have come up as adjunctive tools to conventional periodontal treatment. LANAP, which incorporates free running pulsed Nd:YAG laser, promotes the elusive goal of regeneration of the attachment apparatus facilitating true regeneration. LANAP is a cautiously planned treatment protocol which not only focuses on bactericidal and detoxification effect but also intends to diminish the etiology of the disease. By successful application of these principles, we can further expect long term solutions. Enhanced clinical outcomes and better patient compliance are seen. Continued research and careful observation would open further avenues in terms of periodontal regeneration.

\section{Conflict of Interests}

The authors have no conflict of interest to declare.

\section{Ethical Considerations}

Not applicable.

\section{References}

1. Yukna RA, Carr RL, Evans GH. Histologic evaluation of an Nd:YAG laser-assisted new attachment procedure in humans. Int J Periodontics Restorative Dent. 2007;27(6):577587.

2. Nevins M, Kim SW, Camelo M, Martin IS, Kim D, Nevins M. A prospective 9-month human clinical evaluation of laser-assisted new attachment procedure (LANAP) therapy. Int J Periodontics Restorative Dent. 2014;34(1):2127. doi:10.11607/prd.1848

3. Brown IS. Current advances in the use of lasers in periodontal therapy: a laser-assisted new attachment procedure case series. Clin Adv Periodontics. 2013;3(2):96104. doi:10.1902/cap.2013.120087

4. Katuri KK, Bollepalli AC, Sunkireddy HKR, Chilakalapudi HCB, Kurapati S, Vinnakota NR. Clinical effectiveness of laser assisted new attachment procedure as an adjunct to nonsurgical periodontal treatment: a randomized clinical study. J Int Oral Health. 2015;7(11):57-62.

5. Maiman TH. Stimulated optical radiation in ruby masers. Nature. 1960;187:493-494. doi:10.1038/187493a0

6. Javan A, Bennett WR, Herriott DR. Population inversion and continuous optical maser oscillation in a gas discharge containing a He-Ne Mixture. Phys Rev Lett. 1961;6(3):106110.

7. Sagar K, Kaur A, Patel P, Kumar V, Narang S, Ranga P. Diode laser as an established tool in periodontics - a review. Am J Oral Med Radiol. 2015;2(2):54-60.

8. Fauchard P. The Surgeon Dentist or Treatise on the Teeth (in French). Lindsay L, translator. London: Butterworth; 1946. 
9. Schluger S. Osseous resection; a basic principle in periodontal surgery. Oral Surg Oral Med Oral Pathol. 1949;2(3):316-325.

10. Nabers CL. Repositioning the attached gingiva.JPeriodontol. 1954;25(1):38-39. doi:10.1902/jop.1954.25.1.38

11. Nyman S, Lindhe J, Karring T, Rylander H. New attachment following surgical treatment of human periodontal disease. J Clin Periodontol. 1982;9(4):290-296.

12. Gottlow J, Nyman S, Lindhe J, Karring T, Wennstrom J. New attachment formation in the human periodontium by guided tissue regeneration. Case reports. JClin Periodontol. 1986;13(6):604-616.

13. Vasu A, Hemalata M. Periodontal regeneration - an appraisal. Int J Contemp Dent. 2010;1(2):20-24.

14. Lynch SE, de Castilla GR, Williams RC, et al. The effects of short-term application of a combination of platelet-derived and insulin-like growth factors on periodontal wound healing. J Periodontol. 1991;62(7):458-467. doi:10.1902/ jop.1991.62.7.458

15. Ripamonti U, Reddi AH. Periodontal regeneration: potential role of bone morphogenetic proteins. J Periodontal Res. 1994;29(4):225-235.

16. Gregg RH 2nd, McCarthy D. Laser periodontal therapy: case reports. Dent Today. 2001;20(10):74-81.

17. Gregg RH 2nd, McCarthy D. Laser periodontal therapy for bone regeneration. Dent Today. 2002;21(5):54-59.

18. Nevins ML, Camelo M, Schupbach P, Kim SW, Kim DM, Nevins M. Human clinical and histologic evaluation of laser-assisted new attachment procedure. Int J Periodontics Restorative Dent. 2012;32(5):497-507.

19. Elavarasu S, Naveen D, Thangavelu A. Lasers in periodontics. J Pharm Bioallied Sci. 2012;4(Suppl 2):S260263. doi:10.4103/0975-7406.100245

20. Srivastava P. A review- basics of laser and its role in periodontics. Int J Sci Innov Res. 2015;3(2):43-51.

21. Aoki A, Mizutani K, Schwarz F, et al. Periodontal and periimplant wound healing following laser therapy. Periodontol 2000. 2015;68(1):217-269. doi:10.1111/prd.12080

22. Cobb CM. Lasers in periodontics: a review of the literature. J Periodontol. 2006;77(4):545-564. doi:10.1902/ jop.2006.050417

23. Neill ME, Mellonig JT. Clinical efficacy of the Nd:YAG laser for combination periodontitis therapy. Pract Periodontics Aesthet Dent. 1997;9(6 Suppl):1-5.

24. US Food and Drug Administration. 510(k)s Final Decisions Rendered for July 2004 (PerioLase MVP-7, 510(k) number K030290). http://www.accessdata.fda.gov/cdrh_docs/pdf3/ k030290.pdf. Accessed August 16, 2012.

25. Institute for Advanced Laser Dentistry, University of Colorado School of Dental Medicine. Denver: Lectures and Didactic Manuals, Evolutions 1-5.

26. Robert HG. Introduction to the LANAP protocol for the treatment of periodontitis. C.E. article_LANAP procedure. https://www.lanap.com/site/wp-content/uploads/2016/08/ Dr.-Gregg-CE-article-Laser-2012.pdf.

27. Long CA. New attachment procedure: using the pulsed Nd:YAG laser. Dent Today. 2008;27(2):166-171.

28. Khadtare Y, Chaudhari A, Waghmare P, Prashant S. The LANAP protocol (laser-assisted new attachment procedure) a minimally invasive bladeless procedure. $J$
Periodontal Med Clin Pract. 2014;1(3):264-271.

29. McAllister J. A high-tech approach to managing periodontal disease: case reports. Compend Contin Educ Dent. 2009;30(4):228-230, 232-223.

30. Harris DM, Nicholson DM, McCarthy D, et al. Change in clinical indices following laser or scalpel treatment for periodontitis: A split-mouth, randomized, multi-center trial. Proc SPIE Int Soc Opt Eng. 2014;8929:89290G-1. doi: $10.1117 / 12.2040823$

31. Klinge B, Hultin $M$, Berglundh T. Peri-implantitis. Dent Clin North Am. 2005;49(3):661-676. doi:10.1016/j. cden.2005.03.007

32. Zeza B, Pilloni A. Peri-implant mucositis treatments in humans: a systematic review. Ann Stomatol (Roma). 2012;3(3-4):83-89.

33. Moy PK, Medina D, Shetty V, Aghaloo TL. Dental implant failure rates and associated risk factors. Int J Oral Maxillofac Implants. 2005;20(4):569-577.

34. Tinsley D, Watson CJ, Ogden AR. A survey of U.K. centres on implant failures. J Oral Rehabil. 1999;26(1):14-18.

35. Special report implants by Millennium Dental Technologies: Helping Clinicians Stem the Tide of Failing Implants. Compendium. 2013:34(8).

36. Suzuki JB. Salvaging Implants With an Nd:YAG Laser: A Novel Approach to a Growing Problem. Compend Contin Educ Dent. 2015;36(10):756-61.

37. Harris DM, Yessik M. Therapeutic ratio quantifies laser antisepsis: ablation of Porphyromonas gingivalis with dental lasers. Lasers Surg Med. 2004;35(3):206-213. doi:10.1002/lsm.20086

38. Cobb CM, McCawley TK, Killoy WJ. A preliminary study on the effects of the Nd:YAG laser on root surfaces and subgingival microflora in vivo. $J$ Periodontol. 1992;63(8):701-707. doi:10.1902/jop.1992.63.8.701

39. McCawley TK, McCawley MN, Rams TE. LANAP immediate effects in vivo on human chronic periodontitis microbiota. J Dent Res. 2014;93(Special A):428.

40. Giannelli M, Bani D, Tani A, et al. In vitro evaluation of the effects of low-intensity Nd:YAG laser irradiation on the inflammatory reaction elicited by bacterial lipopolysaccharide adherent to titanium dental implants. J Periodontol. 2009;80(6):977-984. doi:10.1902/ jop.2009.080648

41. Kilinc E, Rothrock J, Migliorati E, Drukteinis S, Roshkind DM, Bradley P. Potential surface alteration effects of laserassisted periodontal surgery on existing dental restorations. Quintessence Int. 2012;43(5):387-395.

42. Stubinger S, Homann F, Etter C, Miskiewicz M, Wieland M, Sader R. Effect of Er:YAG, $\mathrm{CO}(2)$ and diode laser irradiation on surface properties of zirconia endosseous dental implants. Lasers Surg Med. 2008;40(3):223-228. doi:10.1002/lsm.20614

43. Geminiani A, Caton JG, Romanos GE. Temperature change during non-contact diode laser irradiation of implant surfaces. Lasers Med Sci. 2012;27(2):339-342. doi:10.1007/ s10103-010-0876-8

44. Geminiani A, Caton JG, Romanos GE. Temperature increase during $\mathrm{CO}(2)$ and Er:YAG irradiation on implant surfaces. Implant Dent. 2011;20(5):379-382. doi:10.1097/ ID.0b013e3182310d57 
45. Centers for Disease Control and Prevention. National Center for Chronic Disease Prevention and Health Promotion. Division of Diabetes Translation. National Diabetes Statistics Report; 2014.

46. Mealey BL. Periodontal disease and diabetes. A two-way street. J Am Dent Assoc. 2006;137 Suppl:26s-31s.

47. Kiran M, Arpak N, Unsal E, Erdogan MF. The effect of improved periodontal health on metabolic control in type 2 diabetes mellitus. J Clin Periodontol. 2005;32(3):266-272. doi:10.1111/j.1600-051X.2005.00658.x

48. Borgnakke WS, Ylostalo PV, Taylor GW, Genco RJ. Effect of periodontal disease on diabetes: systematic review of epidemiologic observational evidence. J Periodontol. 2013;84(4 Suppl):S135-152. doi:10.1902/jop.2013.1340013

49. Chapple IL, Genco R. Diabetes and periodontal diseases: consensus report of the Joint EFP/AAP Workshop on Periodontitis and Systemic Diseases. J Periodontol. 2013;84(4 Suppl):S106-112. doi:10.1902/jop.2013.1340011

50. Aemaimanan P, Amimanan $\mathrm{P}$, Taweechaisupapong $\mathrm{S}$. Quantification of key periodontal pathogens in insulindependent type 2 diabetic and non-diabetic patients with generalized chronic periodontitis. Anaerobe. 2013;22:6468. doi:10.1016/j.anaerobe.2013.06.010

51. de Andrade AK, Feist IS, Pannuti CM, Cai S, Zezell DM, De Micheli G. Nd:YAG laser clinical assisted in class II furcation treatment. Lasers Med Sci. 2008;23(4):341-347. doi:10.1007/s10103-007-0482-6

52. McCraken T. The LANAP protocol and orthodontics: offering patients hope through collaborative treatment plans. Todays FDA. 2014;26(3):54-5.

53. Gregg RH.World's First-and Only-FDA Clearance for True Regeneration. Compendium. 2016;37(8).

54. Western Society of Periodontics, Periodontics Abstract 2015.

55. Behdin S, Monje A, Lin GH, Edwards B, Othman A, Wang HL. Effectiveness of laser application for periodontal surgical therapy: systematic review and meta-analysis. $J$ Periodontol. 2015;86(12):1352-1363. doi:10.1902/ jop.2015.150212

56. Shah AM, Khan K, Ahmed F, Amir N. A review of the use of laser in periodontal therapy. International Dental Journal of Students' Research. 2015;3(2):79-82. 